\title{
Effect of TiC Particles Concentration on Microstructure and Properties of Ni-TiC Composite Coatings
}

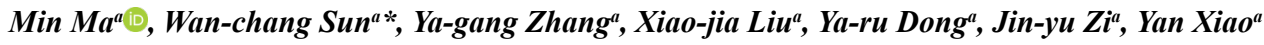 \\ ${ }^{a}$ College of Materials Science and Engineering, Xi'an University of Science and Technology, Xi'an, Shaanxi \\ 710054, P.R.China
}

Received: September 20, 2019; Revised: November 06, 2019; Accepted: November 10, 2019

\begin{abstract}
A kind of novel anti-wear Ni-TiC composite coatings was deposited successfully on $42 \mathrm{CrMo}$ steel by pulsed electrodeposition method with various TiC particles concentration. The effect of TiC concentration on morphologies and properties of Ni-TiC composite coatings were investigated and the optimum concentration of $\mathrm{TiC}$ particle was obtained. Results demonstrate that $\mathrm{TiC}$ particles were distributed uniformly in the Ni-based coatings and $\mathrm{Ni}$-TiC composite coatings consisted of refined nickel nanocrystalline size. When the TiC particles concentration was $32 \mathrm{~g} / \mathrm{L}$, the highest volume percentage of $\mathrm{TiC}$ particles with $23.9 \mathrm{Vol} . \%$ and maximum micro-indentation hardness of the Ni-TiC composite coatings with $475 \mathrm{HV}$ were achieved. Ni-TiC composite coatings show significant improvement in wear resistance in comparison with $\mathrm{TiC}$ free Ni-P coating.
\end{abstract}

Keywords: $\mathrm{Ni}$-TiC composite coatings; pulsed electrodeposition; grain refinement; micro-indentation hardness; friction and wear.

\section{Introduction}

42GrMo steel exhibits remarkable performance such as high strength, good toughness, high hardenability, and small deformation, especially when used as a cutting tool material. However, traditional $42 \mathrm{GrMo} \mathrm{steel} \mathrm{often} \mathrm{has} \mathrm{serious}$ tool wear during processing, which cannot be satisfied with production and processing needs. One of the most effective ways to improve the overall performance of the steel is surface modification to improve tool life and protect internal materials. In recent years, there is an increasing interest in metal-ceramic composite coating ${ }^{1,2}$ due to its excellent mechanical and physical properties.

Among various ceramic particles, $\mathrm{TiC}$ particles is a material of commercial and industrial interest because it is one of the hardest metal carbides with advantages of low density $\left(4.95 \mathrm{~g} / \mathrm{cm}^{2}\right)$, high melting temperature $(3420 \mathrm{~K})$, high bending strength, high fracture toughness, and excellent wear resistance ${ }^{3-5}$, and displays relatively high electrical conductivity and thermal stability ${ }^{6}$. It is considered to be promising candidates for composite reinforcement, which can improve the overall performance of composite materials ${ }^{7}$. The metal nickel possesses a series of excellent properties such as good lubricity, abrasion resistance, corrosion resistance and oxidation resistance ${ }^{8}$. Owing to its high precision electroplating effect, metallic nickel is often used as a metal matrix for composite plating. Nickel composite containing TiC particles have been developed as hard facing for steel mill rolls and as coatings for injection molds. The addition of TiC particles into the nickel matrix can significantly improve the properties of the alloy and its behavior in the services consequently.
For example, Karbasi et al. ${ }^{10}$ prepared Ni-nano-TiC composite coatings by DC electrodeposition in Watt's nickel solution, and found that the composite coatings had better microhardness than the substrate. Such metal-based composites coatings exhibit a wide range of properties to meet specific requirements such as enhanced mechanical properties, high corrosion resistance, and high wear resistance, make it ideal for innovative applications in the aerospace, defense, automobile, and nuclear power industries ${ }^{11}$. Therefore, Ni$\mathrm{TiC}$ composite coatings have wide application prospects.

In the past, the preparation of $\mathrm{Ni}-\mathrm{TiC}$ composite coatings mainly focuses on laser cladding ${ }^{12,13}$, thermal spray ${ }^{14}$ and other processes $^{15-19}$. However, a major problem with those kinds of processes is carried out under high-temperature conditions. Due to the great difference in thermophysical properties between the metal matrix and the ceramic phase, the coating obtained by laser cladding is highly sensitive to crack, which is easy to cause the coating spalling. Furthermore, the volume content of particles in the composite coatings prepared by conventional electroless plating is insufficient to satisfy the practical application requirements of certain special fields ${ }^{20}$.

Electrodeposition is part of the most reliable ways to obtain nanostructured coatings with enhanced mechanical and electrochemical properties ${ }^{21,22}$. In the process of producing composite coatings, the electrodeposition has been demonstrated to have a smoother surface, a better bonding between particles and metal, as well as higher micro-hardness ${ }^{23}$. It also has advantages of low porosity ${ }^{24}$, low temperatures, low cost, high deposition rate and single-step process without additional heat treatment ${ }^{25}$. Up to now, limited investigations have been made on pulse electrodeposition to provide composite coating with $\mathrm{TiC}$ particles. 
According to Ataie and Zakeri ${ }^{26}$, compared with the traditional DC method, the $\mathrm{Zn}-\mathrm{Ni}-\mathrm{Al}_{2} \mathrm{O}_{3}$ composite coatings prepared by the pulse plating method has a significant improvement in tribological properties such as leveling out the surface roughness and reducing coatings microcracks. Ghazanlou et al. ${ }^{27}$ produced successfully $\mathrm{Ni}-\mathrm{Co} / \mathrm{SiO}_{2}$ nanocomposites from Watt's nickel bath through direct and pulse electrodeposition. They pointed out that the micro-hardness of nanocomposites prepared by pulse current is superior to that of nanocomposites prepared by direct current.

In this research work, pulse electrodeposition of $\mathrm{Ni}$-TiC composite coatings with various $\mathrm{TiC}$ particles concentration was produced, aiming to refine the nickel grain size as well as improve the wear resistance of the composite coating, and determine the optimum values of TiC particles concentration. Furthermore, the effect of $\mathrm{TiC}$ particles concentration on matrix grain size, deposited volume fraction of TiC, microindentation hardness, friction coefficient, and wear resistance of the composite coatings was investigated and the wear mechanism was also discussed.

\section{Materials and Methods}

\subsection{Preparation of Ni-TiC composite coatings}

$42 \mathrm{CrMo}$ steel substrates with a dimension of $17 \mathrm{~mm} \times 11$ $\mathrm{mm} \times 7 \mathrm{~mm}$ were polished initially with an abrasive paper of $320,600,1000,1500,2000$ grits by sequence to remove impurities. The specimens were then ultrasonically cleaned in acetone for $15 \mathrm{~min}$ and degreased in alkaline solution at 50 ${ }^{\circ} \mathrm{C}$ for $10 \mathrm{~min}$. To eliminate the oxide film, each all specimens in $10 \% \mathrm{HCl}$ solution $12 \mathrm{~s}$, then rinsed with distilled water. In the end, the treated substrates after air-dried were used as cathode, and placed vertically and paralleled to two nickel anode plates of $99.9 \%$ purity at a distance of $10 \mathrm{~mm}$, along with a power supply. The surface area of the anode was chosen to be approximately five times greater than that of the cathode to ensure that the anodic polarization of nickel does not cause any problems ${ }^{10}$. The schematic of the pulse electrodeposition setup is illustrated in Fig.1.

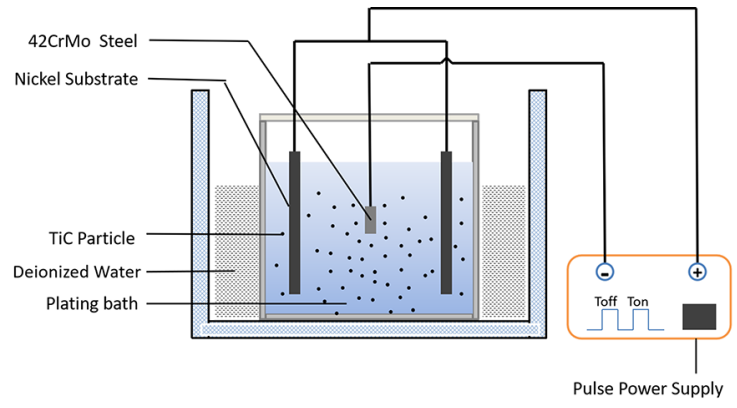

Figure 1. Schematic of pulse electrodeposition

$\mathrm{Ni}$-TiC composite coatings were electrodeposited from an organic free Watts' nickel electrolyte with differently suspended TiC particles concentration of $8 \mathrm{~g} / \mathrm{L}, 16 \mathrm{~g} / \mathrm{L}$, $24 \mathrm{~g} / \mathrm{L}, 32 \mathrm{~g} / \mathrm{L}$, and $40 \mathrm{~g} / \mathrm{L}$, respectively. The chemical composition and process parameters of the electrodeposition are given in Table 1. The $\mathrm{TiC}$ particles were used without any pretreatment and held in suspension in the electrolytic bath by continuous magnetic stirring to maintain a uniform concentration of particles in the bulk solution. To prevent the TiC particles agglomeration, the electrolyte was placed in the ultrasonic bath for 30 min originally.

\subsection{Characterization}

The surface morphologies and cross-section micrographs of the Ni-TiC composite coatings were analyzed by scanning electron microscopy (SEM) (JSM-6390A, Japan) and optical microscope (EM-1500L). The crystal structure of the coating was examined by X-ray diffractometer (XRD) (XRD-7000, Japan) with $\mathrm{Cu} \mathrm{K} \alpha$ radiation in $35 \mathrm{kV}$, and scanning range of $2 \theta=20-80^{\circ}$, the incident wavelength of $\lambda=0.154060$ $\mathrm{nm}$, the current of $30.0 \mathrm{~mA}$. The grain size of nickel matrix was calculated by the Scherrer Equation (2.1):

$$
d=K \lambda / \beta \cos \theta
$$

Where $d$ is the grain average size, $K$ is Scherrer constant of $0.89, \lambda$ is characteristic X-ray wavelength of 0.154056 $\mathrm{nm}, \theta$ is the angle of diffraction, $\beta$ is the diffraction peak semi-height width (radians).

Table 1. Electrodeposition bath composition and process parameters

\begin{tabular}{cc}
\hline Bath composition and technology & Concentration and working condition \\
\hline $\mathrm{NiSO}_{4} \cdot 6 \mathrm{H}_{2} \mathrm{O}$ (nickel sulfate hexahydrate) & $400 \mathrm{~g} / \mathrm{L}$ \\
$\mathrm{NiCl}_{2} \cdot 6 \mathrm{H}_{2} \mathrm{O}$ (nickel chloride hexahydrate) & $50 \mathrm{~g} / \mathrm{L}$ \\
$\mathrm{H}_{3} \mathrm{BO}_{3}$ (boric acid) & $60 \mathrm{~g} / \mathrm{L}$ \\
$\mathrm{TiC}$ particles & $0 \sim 40 \mathrm{~g} / \mathrm{L}$ \\
Stir rate & $200 \mathrm{r} / \mathrm{min}$ \\
Current density & $1 \mathrm{~A} / \mathrm{dm}^{2}$ \\
Temperature & $80{ }^{\circ} \mathrm{C}$ \\
pH & $5.0 \sim 6.0$ \\
Duty ratio & $50 \%$ \\
\hline
\end{tabular}


The mass fraction of $\mathrm{TiC}$ particles in the coatings was examined by energy dispersive spectroscopy (EDS) coupled to the SEM. Taking three points on the surface of the coating, the mass fraction of $\mathrm{Ni}$ and $\mathrm{Ti}$ elements were determined and the values are the average resulted from these measurements. The volume fraction of TiC particles in the composite coatings could be calculated according to the following relationships:

$$
\begin{gathered}
W_{T i C}=\frac{M_{T i C}}{M_{T i C}} \times W_{T i} \\
V o l_{T i C}=\frac{W_{T i C} / \rho_{T i C}}{W_{T i C} / \rho_{T i C}+W_{N i} / \rho_{N i}}
\end{gathered}
$$

Where $W_{T i C}, W_{T i}, W_{N i}$ are the mass fraction (\%) of TiC, Ti and $\mathrm{Ni}$ in the composite coatings, $M_{T T C}$ and $M_{T i}$ are the molar mass ( $\mathrm{g} / \mathrm{mol})$ of TiC and $\mathrm{Ti}, \mathrm{Vol}_{T i C}$ is the volume fraction (\%) of TiC particles in the composite coatings, while $\rho_{T i C}$ and $\rho_{N i}$ are the density of $\mathrm{TiC}$ particles and $\mathrm{Ni}$ matrix.

The micro-indentation hardness of the Ni-TiC composite coatings was measured by Vickers micro-indentation hardness tester (EM-1500L, Hengyi Instruments LTD, Shanghai, China) under a load of $50 \mathrm{gf}$ for $5 \mathrm{~s}$. The final value quoted for the hardness of a deposit was the average of four measurements.

The wear resistance of the Ni-TiC composite coatings was examined by a ball disk type high-temperature friction and wear tester (HT-1000) under dry sliding conditions at room temperature. The test used a $\mathrm{Si}_{3} \mathrm{~N}_{4}$ grinding ball $(6 \mathrm{~mm}$ diameter) for $15 \mathrm{~min}$ under a $5 \mathrm{~N}$ load. The weight loss of the coating was measured by weighing the samples before and after each wear test, using an electronic balance with a precision of $0.01 \mathrm{mg}$. The friction coefficient was recorded automatically during the test.

\section{Results and Discussion}

\subsection{Cross-section morphologies and composition of $\mathrm{Ni}$-TiC composite coatings}

The cross-section morphologies of Ni-TiC composite coatings with $32 \mathrm{~g} / \mathrm{L} \mathrm{TiC}$ particles added in the bath are shown in Fig. 2. The good adhesion between the coating and the substrate was observed as shown in Fig. 2a. Apparently, there were no obvious pores and cracks at the interface. Fig. $2 b$ shows the high-magnification image of the cross-section morphology. From the micrograph, it is evident that $\mathrm{Ni}-\mathrm{TiC}$ composite coatings had a larger volume fraction of particles and the incorporated particles were uniformly distributed in the nickel matrix. As can be seen, there is no obvious agglomeration of TiC particles. The thickness of the coating is about $217 \mu \mathrm{m}$ after 2 hours of plating. Simultaneously, it can be found in Fig. $2 b$ that the particle diameter of most of the $\mathrm{TiC}$ particles deposited in the coating is approximately $2-3 \mu \mathrm{m}$, and that there were very few particles of excessive diameter, indicating that pulse electrodeposition has a screening effect on the size. In other words, the particles of a certain size range are not difficult to be caught by coating. It is because that small particle is easier to be coated completely when the constant current is switched on. For larger particles, only part of them are embedded in nickel matrix, and when current is turned off, large particles that have not been firmly embedded in the matrix metal are likely to re-enter the bath off the surface of the cathode owing to the scouring effect of the plating bath, so the larger particles cannot be captured by the coating. Therefore, the selective co-deposition of particles in the bath can be realized in the pulse composite plating process.
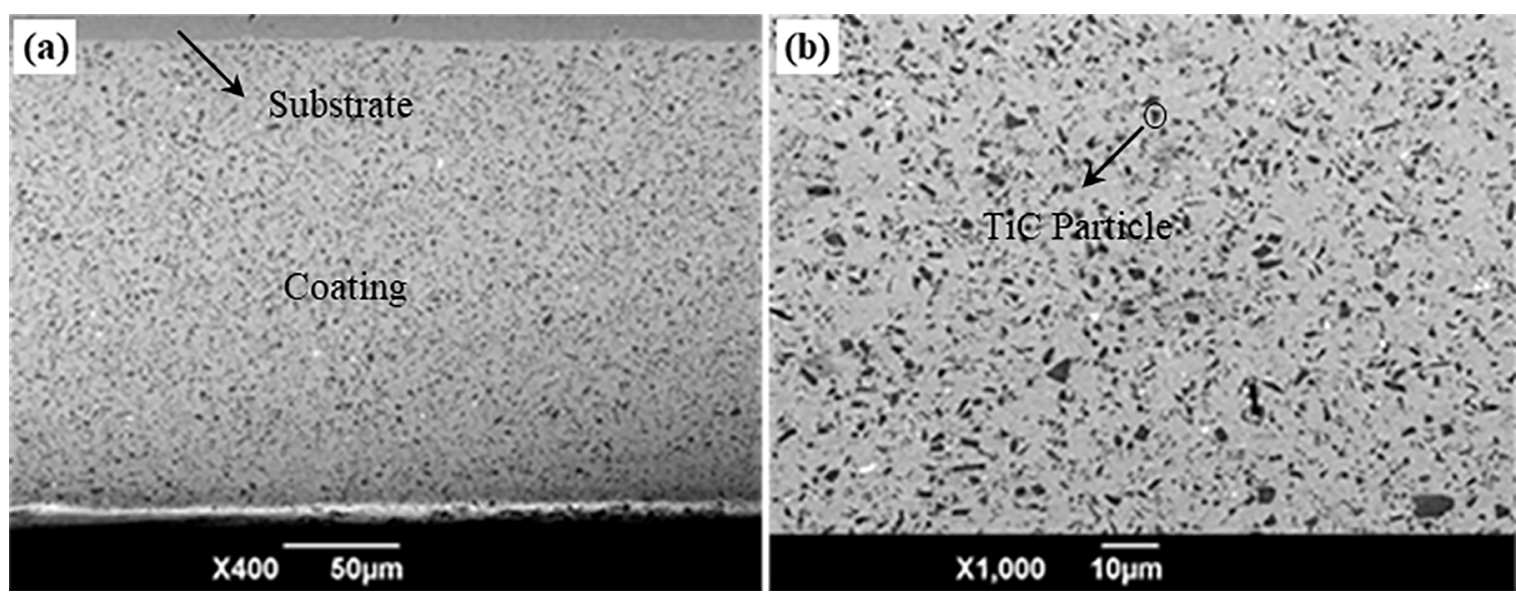

Figure 2. Cross-section SEM micrographs of Ni-TiC composite coatings 
Distribution of $\mathrm{Ni}$, Ti and $\mathrm{C}$ atoms were revealed by EDS spectra carried out with a SEM, as showed in Fig. 3. It is indicated that the $\mathrm{Ni}, \mathrm{Ti}$ and $\mathrm{C}$ atoms were enriched in the coating. Therefore, it can be proven that the TiC particles were uniformly dispersed across the composite layer.

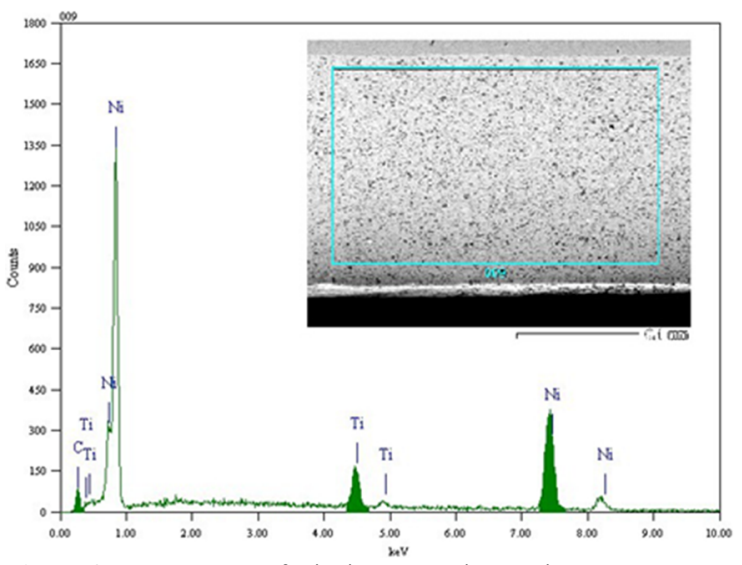

Figure 3. EDS spectra of Ni-TiC composite coatings

\subsection{The surface morphologies of Ni coating and $\mathrm{Ni}$-TiC composite coatings}

The surface morphologies of $\mathrm{Ni}$ coating and $\mathrm{Ni}-\mathrm{TiC}$ composite coatings are shown in Fig. 4. The SEM micrographs of Ni coating, as depicted in Fig. $4 \mathrm{a}$ and b, show that the morphology of electrodeposited nickel is made up of regular granular and the microstructure is inhomogeneous.
Similarly, Fig. 4c and d present the images of Ni-TiC composites coatings, which reveal that the structure of nickel deposits transform from the granular structure to quasi-sphere cauliflower structure. The smooth and compact microstructure of coating was observed. The $\mathrm{TiC}$ particles precipitated in nickel structure, and nickel grain growth was obstructed by TiC particles located in grain boundaries.

\subsection{The phase analysis of $\mathrm{Ni}$-TiC composite coatings}

The XRD patterns of $\mathrm{Ni}$ coating and $\mathrm{Ni}-\mathrm{TiC}$ composite coatings are shown in Fig. 5. As showed in Fig. 5a, typical peaks at $44.507^{\circ}, 51.846^{\circ}$ and $76.380^{\circ}$ corresponding to the $\mathrm{Ni}$ coating with crystallographic planes of (111), (200) and (220), respectively. It is shown that the $\mathrm{Ni}$ deposited in the coating is a face-centered cubic (fcc) crystal structure. The characteristic peaks of $\mathrm{TiC}$ particles were observed in Fig. 5b, indicating the incorporation of a large fraction of $\mathrm{TiC}$ particles in Ni coating. The diffraction peaks of $\mathrm{TiC}$ particles appeared at the angles of $2 \theta=35.906^{\circ}, 41.710^{\circ}$ and $60.448^{\circ}$, which belong to the planes of (111), (200) and (220), respectively. In the composite coatings, the position of the three strong peaks of $\mathrm{Ni}$ was not changed, and the diffraction peak of (200) was obviously weakened, which indicates that the crystal preferred orientation of the composite coatings was transformed from the crystal face (200) to (111) compared with Ni coating. The preferred orientation of $\mathrm{Ni}$ crystal can be explained according to the crystallographic theory.
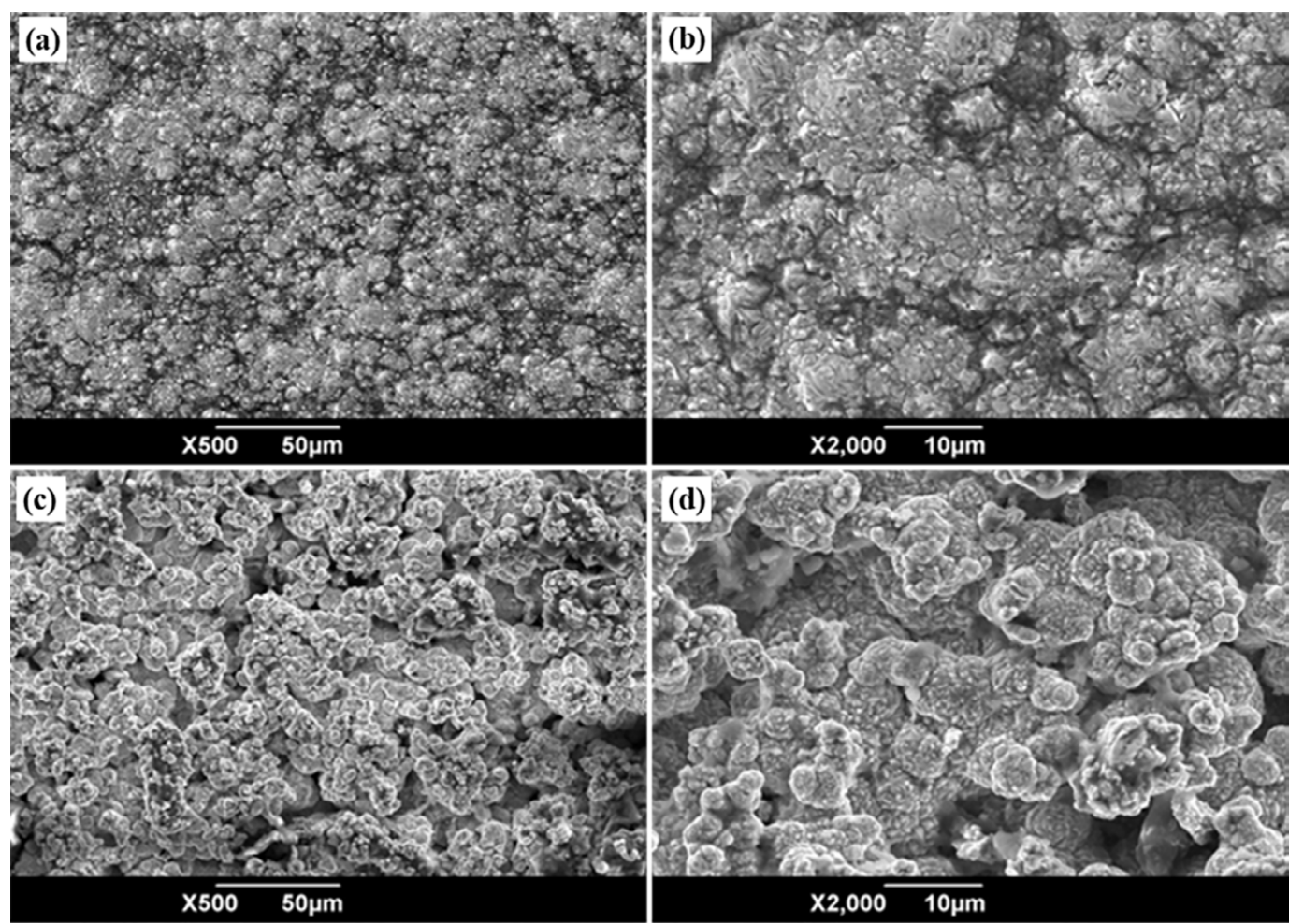

Figure 4. Surface SEM images of coatings: (a) and (b) Ni coating; (c) and (d) Ni-TiC composite coatings 
The deposited nickel has a face-centered cubic lattice; the atomic plane packing density $\left(4 / \sqrt{3} \mathrm{a}^{2}\right)$ of (111) is higher than the atomic density $\left(2 / \mathrm{a}^{2}\right)$ of $(200)$. And compared with the planes of (200), the surface energy of the (111) is lower, so the atoms tend to diffuse to the (111) plane that with higher atomic packing density.

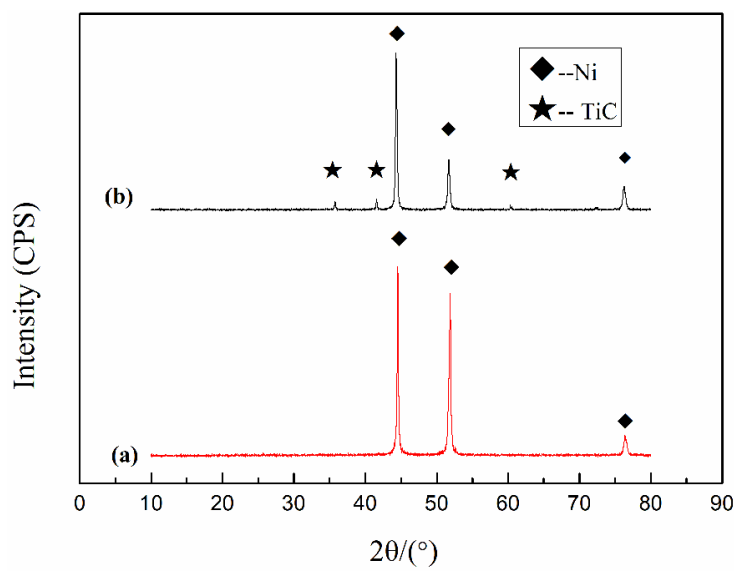

Figure 5. X-ray diffraction patterns of coatings as-plated: (a) Ni coating; (b) Ni-TiC composite coatings

\subsection{Effect of TiC particles concentration on volume fraction of particles and cross-section morphologies of composite coatings}

The mess fraction of $\mathrm{Ni}$ and $\mathrm{Ti}$ elements of composite coatings with different $\mathrm{TiC}$ particles concentration determined by EDS are shown in Table 2. The volume fraction of particles in the coating from different $\mathrm{TiC}$ particles concentration could be calculated with Eq 2.2 and 2.3, results as shown in Fig. 6 .

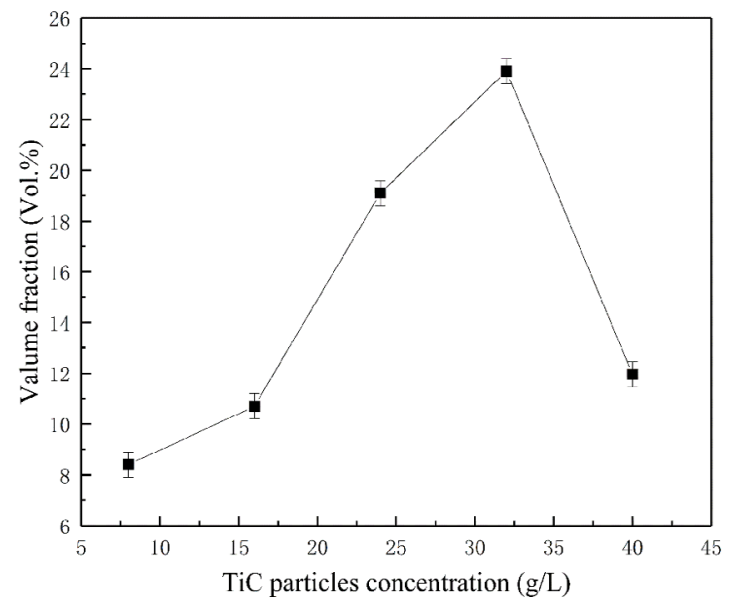

Figure 6. Effects of TiC concentration on the volume fraction of TiC particles in composite coatings
As can be clearly seen in Fig. 6 the volume fraction of TiC particles in the coating increases initially and then decreases with increasing the concentration of $\mathrm{TiC}$ particles in the plating bath. The volume fraction of $\mathrm{TiC}$ particles reaches the maximum value of $23.9 \mathrm{vol} \%$ when the TiC particles concentration is $32 \mathrm{~g} / \mathrm{L}$, further increasing the TiC particles concentration in the plating bath, the volume fraction of TiC particles in the costing decreases.

The cross-section morphologies of the composite coatings prepared by increasing the concentration of $\mathrm{TiC}$ particles from $8 \mathrm{~g} / \mathrm{L}$ to $40 \mathrm{~g} / \mathrm{L}$ are shown in Fig. 7. As can be seen, the content of TiC particles in the coating is very small and the coating is thin when the concentration of TiC particles is $8 \mathrm{~g} / \mathrm{L}$. With the increase in TiC particles concentration, the distribution of $\mathrm{TiC}$ particles in the coating increases gradually. The deposition amount of TiC particles is more and evenly distributed among the coating when the concentration of $\mathrm{TiC}$ particles in the bath reaches $32 \mathrm{~g} / \mathrm{L}$. The reason for this phenomenon is that when the concentration of $\mathrm{TiC}$ particles in the plating increases in a certain range, the amount of suspended particles increases, and the number of particles transported to the surface of the cathode by stirring in a unit time increases accordingly, the higher the probability of particles entering the coating, and the higher the volume fraction of TiC particles in the coating. When the concentration of $\mathrm{TiC}$ particles exceeds a certain value, the irregular movement towards the particles in the plating bath will hinder the directional movement towards metal ions to the cathode, and the content of TiC particles in the coating will decrease. Furthermore, the excess TiC particles would limit the combined ability of TiC particles and make highly agglomeration, which is difficult to be adsorbed by the cathode surface or easy to fall off under the action of bath scour and impact, thus reducing the content of TiC particles. In addition, Guglieimi theory ${ }^{28}$ (3.1) suggested that at first step, particles are absorbed weakly at the cathode by the Van der Waals' force; at the second step, particles are adsorbed strongly on the cathode by Coulomb force and consequently, are buried with the depositing metals.

$$
\frac{\left(1-\alpha_{v}\right) C_{v}}{\alpha_{v}}=\frac{W i_{0}}{n F \rho_{m} V_{0}} e^{(A-B) \eta}\left[\frac{1}{K}+C_{v}\right]
$$

Where $\alpha_{v}$ is the amount of eutectoid, $C_{v}$ is the particle concentration in plating solution, $F$ is Faraday constant, $W$ is the relative atomic weight of coated metals, $\rho_{m}$ is the density of coated metals, $n$ is the number of electrons obtained from coated metals, $\eta$ is cathode over-potential, $i_{o}$ is current density, $A 、 B 、 K 、 V_{o}$ are constants.

Table 2. Mass fraction of $\mathrm{Ni}$ and $\mathrm{Ti}$ element of composite coatings with different $\mathrm{TiC}$ concentration in bath

\begin{tabular}{cccccc}
\hline TiC concentration in bath $(\mathrm{g} / \mathrm{L})$ & 8 & 16 & 24 & 32 & 40 \\
\hline Mass fraction of $\mathrm{Ni}(\mathrm{wt} \%)$ & 91.25 & 81.74 & 80.49 & 78.31 & 86.97 \\
Mass fraction of $\mathrm{Ti}(\mathrm{wt} \%)$ & 3.87 & 8.56 & 8.76 & 11.34 & 5.45 \\
\hline
\end{tabular}



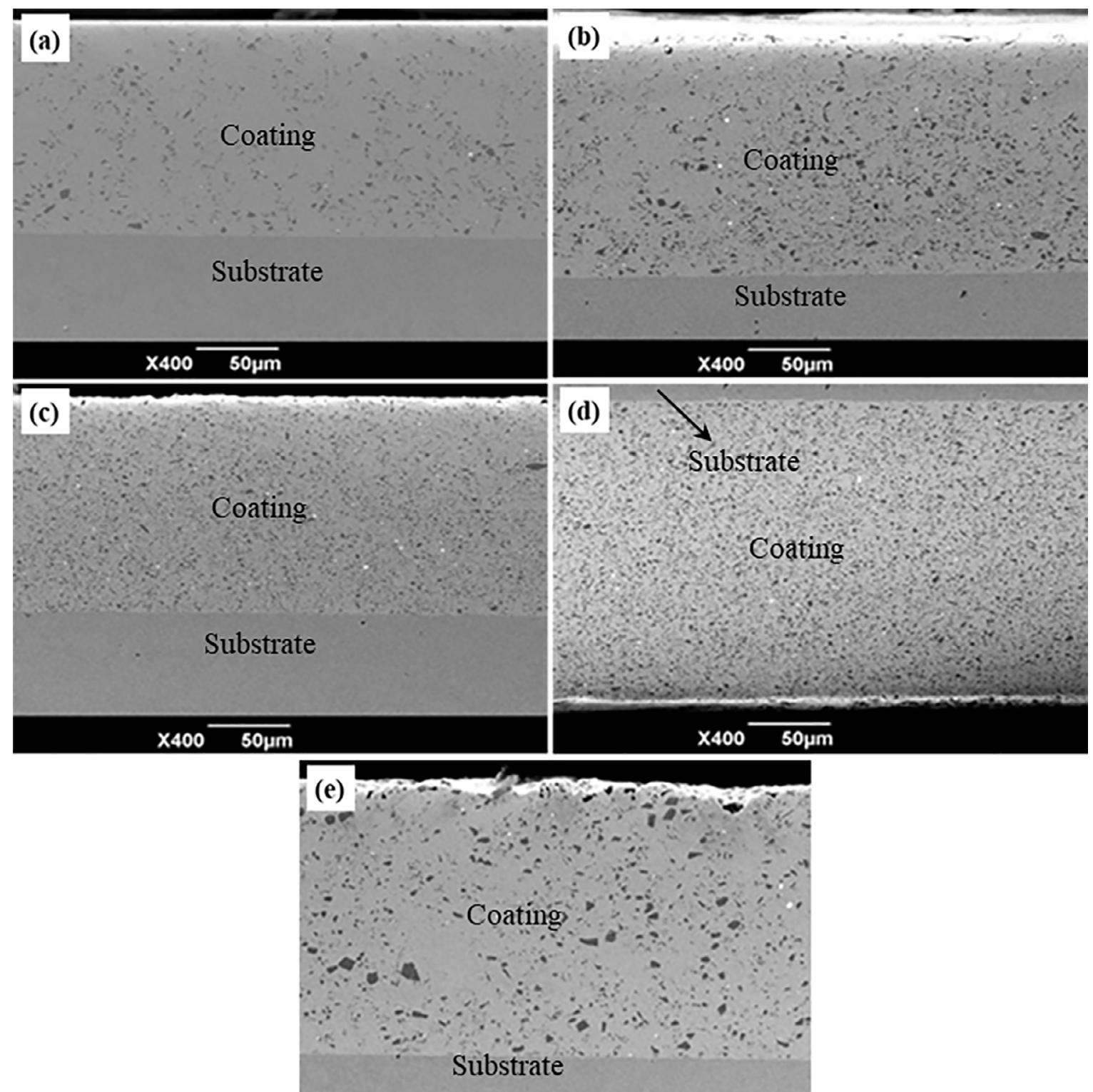

$\times 4 0 0 \longdiv { 5 0 \mu m }$

Figure 7. Cross-section SEM images of composite coatings with different TiC particles concentration in solution: (a) $8 \mathrm{~g} / \mathrm{L}$; (b) $16 \mathrm{~g} / \mathrm{L}$; (c) $24 \mathrm{~g} / \mathrm{L}$; (d) $32 \mathrm{~g} / \mathrm{L}$ and (e) $40 \mathrm{~g} / \mathrm{L}$

\subsection{Effect of TiC particles concentration on $\mathrm{Ni}$ matrix grain size}

The relationship between Ni matrix grain sizes of $\mathrm{Ni}$-TiC composite coatings and the concentration of $\mathrm{TiC}$ particles in the plating bath is presented in Fig. 8. Increasing the TiC particles concentration resulted in decreasing $\mathrm{Ni}$ matrix grain sizes. Therefore, a minimum grain size of $55.01 \mathrm{~nm}$ was obtained when $\mathrm{TiC}$ particles concentration was $32 \mathrm{~g} / \mathrm{L}$. However, by increasing the $\mathrm{TiC}$ particles concentration to $40 \mathrm{~g} / \mathrm{L}$, the grain size was increased sharply. By contrast, the grain size of the $\mathrm{Ni}$ matrix in $\mathrm{Ni}-\mathrm{TiC}$ composite coating is smaller than that of $\mathrm{Ni}$ coating, which indicates that $\mathrm{TiC}$ particles play the role of refining grain.
The decrease in the grain size of the Ni matrix can be explained by the fact that the uniformly distributed $\mathrm{Ni}$ embryos and $\mathrm{TiC}$ particles in the Ni matrix restrain the growth of the $\mathrm{Ni}$ grains. During the sedimentary process, TiC particles are dispersed in the matrix, which provides a large number of second phase heterogeneous nucleation points for $\mathrm{Ni}^{2+}$ deposition, and the nucleation is preferentially attached to the surface of the particles, thus increasing the number of grains. The higher the TiC particles content in coating, the more nucleation points provided for the nickel atoms, and the more pronounced the grain refining effect. On the other hand, the TiC particles dispersed at the nickel grain boundary inhibit the growth of the $\mathrm{Ni}$ grains ${ }^{29}$, resulting in a decrease in grain size and a compact microstructure. 


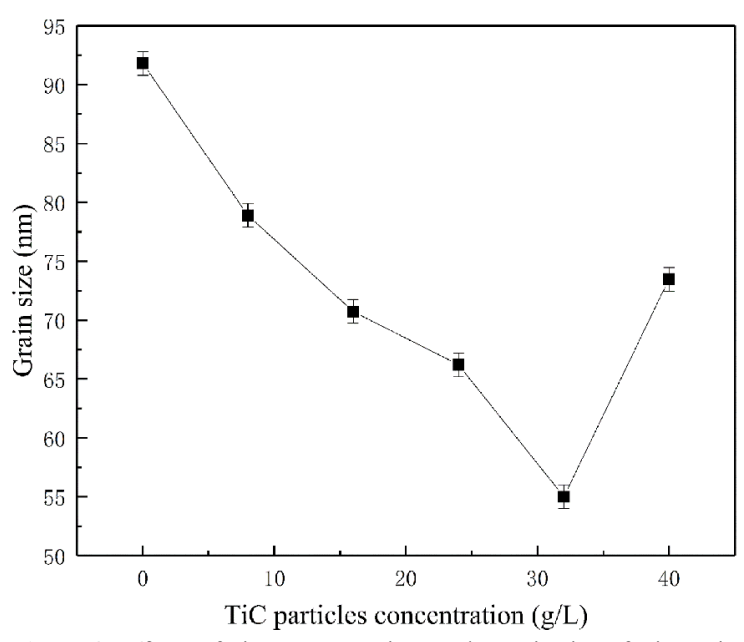

Figure 8. Effects of TiC concentration on the grain size of Ni matrix

Also, the deposited TiC particles have a polarization effect on the reduction deposition of nickel, which because the deposited TiC particles partially cover the cathode surface, causing uneven current density, thereby increasing the local current density and the over-potential of the cathode, and then promoting crystal nucleation, increasing the number of nucleation greatly. Due to the crystal growth rate is invariable, thus the coating obtained refined grain.

\subsection{Effect of TiC particles concentration on micro-indentation hardness of $\mathrm{Ni}$-TiC composite coatings}

The plot of micro-indentation hardness versus the concentration of $\mathrm{TiC}$ particles for $\mathrm{Ni}$-TiC composite coatings is shown in Fig. 9. From the plot, it is seen that the microindentation hardness increases initially and then decreases, and maximum micro-indentation hardness value of 475 $\mathrm{HV}$ was found for Ni-TiC composite coatings at the TiC particles concentration of $32 \mathrm{~g} / \mathrm{L}$. The increasing hardness of the composite coatings can be attributed to dispersion strengthening, Orowan hardening mechanism, and grain refinement. On the one hand, the high content and uniform distributed $\mathrm{TiC}$ particles are strongly combined with the $\mathrm{Ni}$ matrix, which improves the dispersion strengthening effect. On the other hand, according to the hardening mechanism of Orowan, the dislocations bow around $\mathrm{TiC}$ particles that act as dislocation pinning sites increasing the flow stress which is inversely proportional to the particle dispersion. So the particle dispersion decrease and the flow stress increase with the increase of volume fraction of $\mathrm{TiC}$ particles in the coating. Therefore, the hardness of the coating increases with the increase of the volume fraction of $\mathrm{TiC}$ particles in the coating. Besides, the particles dispersed in the matrix play a role in grain refinement. After grain refinement, the plastic deformation of fine-grain requires greater external force.
According to the Hall-Petch relation, the hardness of the coating is inversely proportional to the square root of the grain size. So, with the increases of volume fraction of the $\mathrm{TiC}$ particles, the crystal size of the Ni matrix decreases and the hardness of composite coatings increase. However, when the content of $\mathrm{TiC}$ particles was further increased, the excessive $\mathrm{TiC}$ particles agglomerated and coagulated in the electrodeposition solution. These agglomerates were deposited on the surface of the coating, which would cause stress concentration around the $\mathrm{TiC}$ particles and reduce cohesion. Microcrack would generate in the coating resulting in a decrease in the micro-indentation hardness of the composite coatings.

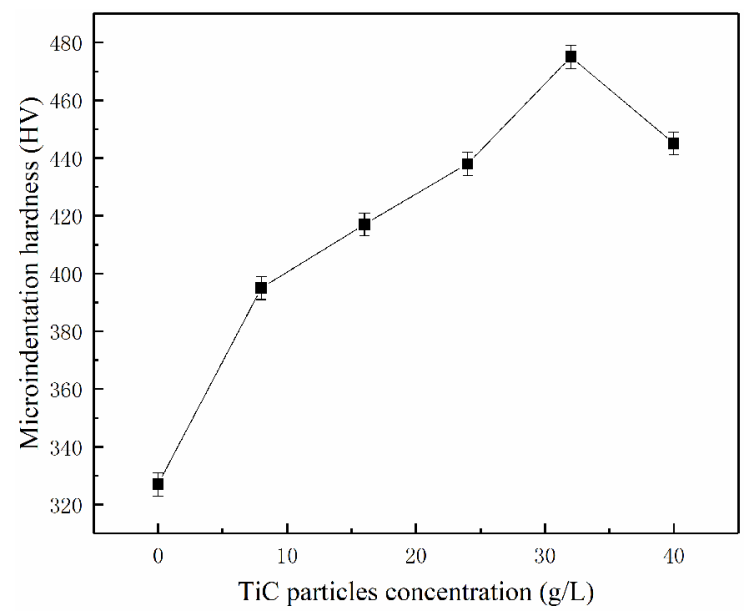

Figure 9. Effects of $\mathrm{TiC}$ particles concentration on micro-indentation hardness of Ni-TiC composite coatings

\subsection{Effect of TiC particles concentration on friction and wear properties of $\mathrm{Ni}-\mathrm{TiC}$ composite coatings}

To explore the wear mechanism of the composite coating and optimize the preparation process of such coatings, the friction mechanism (shown in Fig. 10) was discussed.

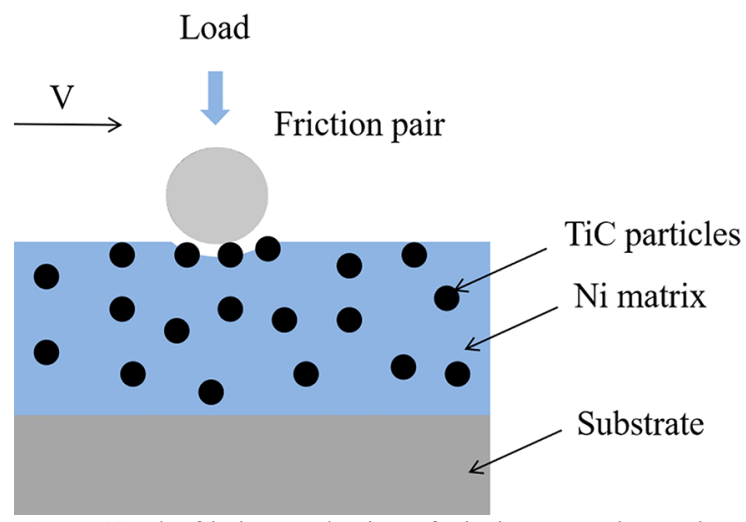

Figure 10. The friction mechanism of Ni-TiC composite coatings 
As illustrated, the $\mathrm{TiC}$ particles uniformly disperse in the $\mathrm{Ni}$ $\mathrm{TiC}$ composite coatings. The convex TiC particles could play a supporting role, so that the composite coating has a certain deformation resistance, thereby reducing the actual contact area of the composite coatings in the wear process. The content of hard TiC particles in the composite coatings is high, and it can make full use of the excellent properties of TiC particles, thus improving the wear resistance of the composite coatings.

In the present research, the anti-friction and wear resistance of Ni-TiC composite coatings were examined under the ballon-disk configuration. Fig. 11 plots the wear rate of the five deposited composite coatings. The wear rate first decreases and then slightly increases with the increasing $\mathrm{TiC}$ particles concentration. When the concentration of TiC particles is 32 $\mathrm{g} / \mathrm{L}$, the wear rate is the lowest. Fig. 12 shows the relationship between $\mathrm{TiC}$ particles concentration and the friction coefficient. With the increasing $\mathrm{TiC}$ particles concentrations from 0 to $40 \mathrm{~g} / \mathrm{L}$ in the bath, the average friction coefficient of the coatings initially decreases and then increases. This is in good agreement with the wear rate results discussed above. These results are attributed to the reduction of grain size. The presence of finer grains, indicating an enlargement of the grain boundaries, hinders the dislocation motion resulting in an improvement in hardness, as well as the yield strength of the composite coatings. The hardness and yield strength of $\mathrm{Ni}$-TiC composite coatings increased with the increase of $\mathrm{TiC}$ particles concentration and the uniform distribution of $\mathrm{TiC}$ particles in the coating, the wear rate decreases remarkably. However, the agglomeration of the particles in the coating increased with the concentration of TiC particles increases, and the adhesion between agglomerated particles is very poor. Herein, it is easy for these agglomerated particles to fall off during friction and wear, resulting in more serious wear.

The SEM images of worn surfaces of Ni-TiC composite coatings with different concentrations of TiC particles under the same load and loading time are presented in Fig. 13.

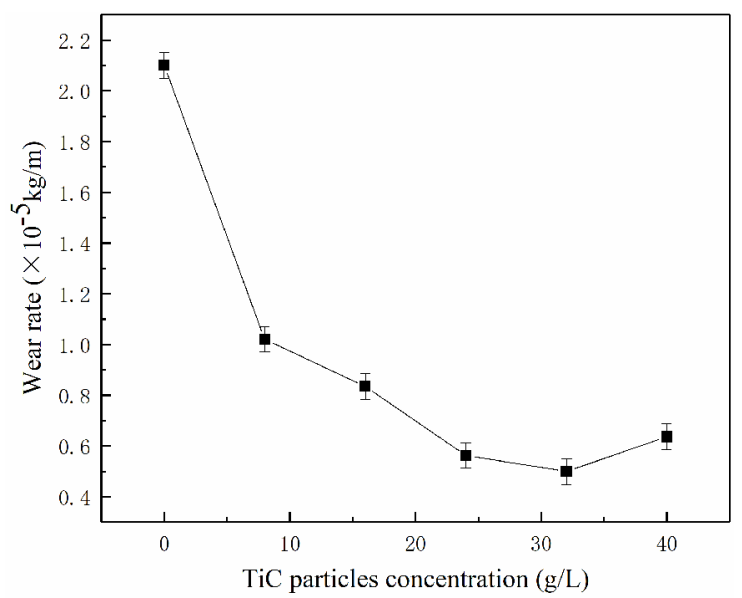

Figure 11. Effects of $\mathrm{TiC}$ concentration on the wear rate of $\mathrm{Ni}$-TiC composite coatings
As seen from these images, the $\mathrm{TiC}$ particle content of the composite coatings has a large influence on the wear morphology. As can be seen from Fig. 13a, there is a large amount of debris and delamination on the surface of $\mathrm{Ni}$ coating, indicating that the wear mechanism of $\mathrm{Ni}$ coating is typical adhesive wear. When the addition of TiC particles is $8 \mathrm{~g} / \mathrm{L}$ (Fig. 13b), there are obvious plowing and adhesion peeling marks on the surface of the composite coating, which showed the characteristics of adhesion wear. The micro-indentation hardness of the coating presents low value, and plastic deformation occurs during wear with a large amount of wear.

With the increase of TiC particles concentration in the bath, more deposited TiC particles appear in the composite coatings, some particles are not covered with Ni matrix on the outer surface of the coating and then bear the load transfer from the matrix during the sliding processes. Thus, the wear changes from the original ceramic-metal wear to the ceramicceramic-metal wear. What is more, due to the high hardness and high strength of TiC particles, plastic deformation such as breakage and scratch is not easy to occur in the process of wear, so the plowing and adhesion wear can be effectively suppressed. As shown in Fig. 13e, when the addition of TiC particles increased to $32 \mathrm{~g} / \mathrm{L}$, the wear scar is smooth and narrow with slight scratches, and the wear resistance of the coating is obviously improved. Although the TiC particles possess an excellent performance, the wear amount will increase and therefore the micro-indentation hardness will decrease, with excessive TiC particles adding in the plating bath, as proved in Fig. 9. Excessive particle concentration tends to cause local enrichment and agglomeration. The agglomerates deposited in the coating are easy to cause stress concentration around the particles, resulting in the wide wear scar and thus the low wear resistance. This is the reason why the wear scar in Fig. 13f is wider and deeper than that in Fig. 13e.

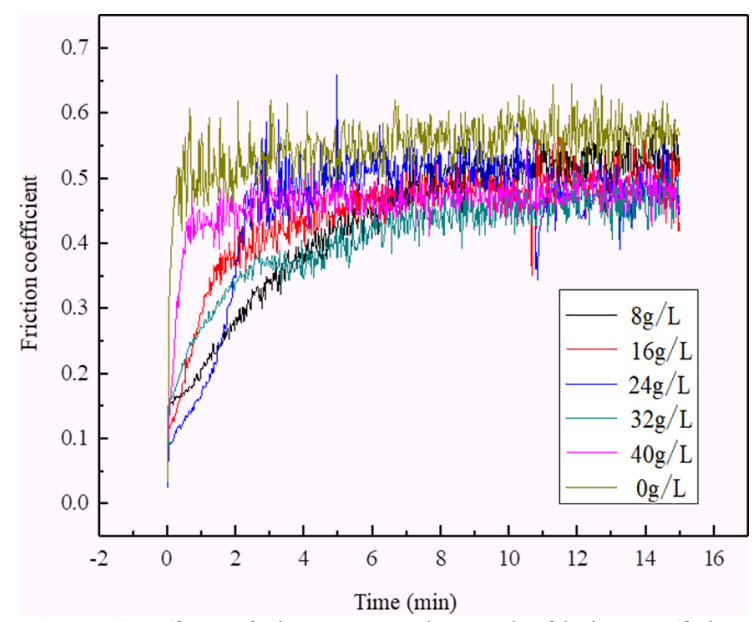

Figure 12. Effects of TiC concentration on the friction coefficient of $\mathrm{Ni}$-TiC composite coatings 

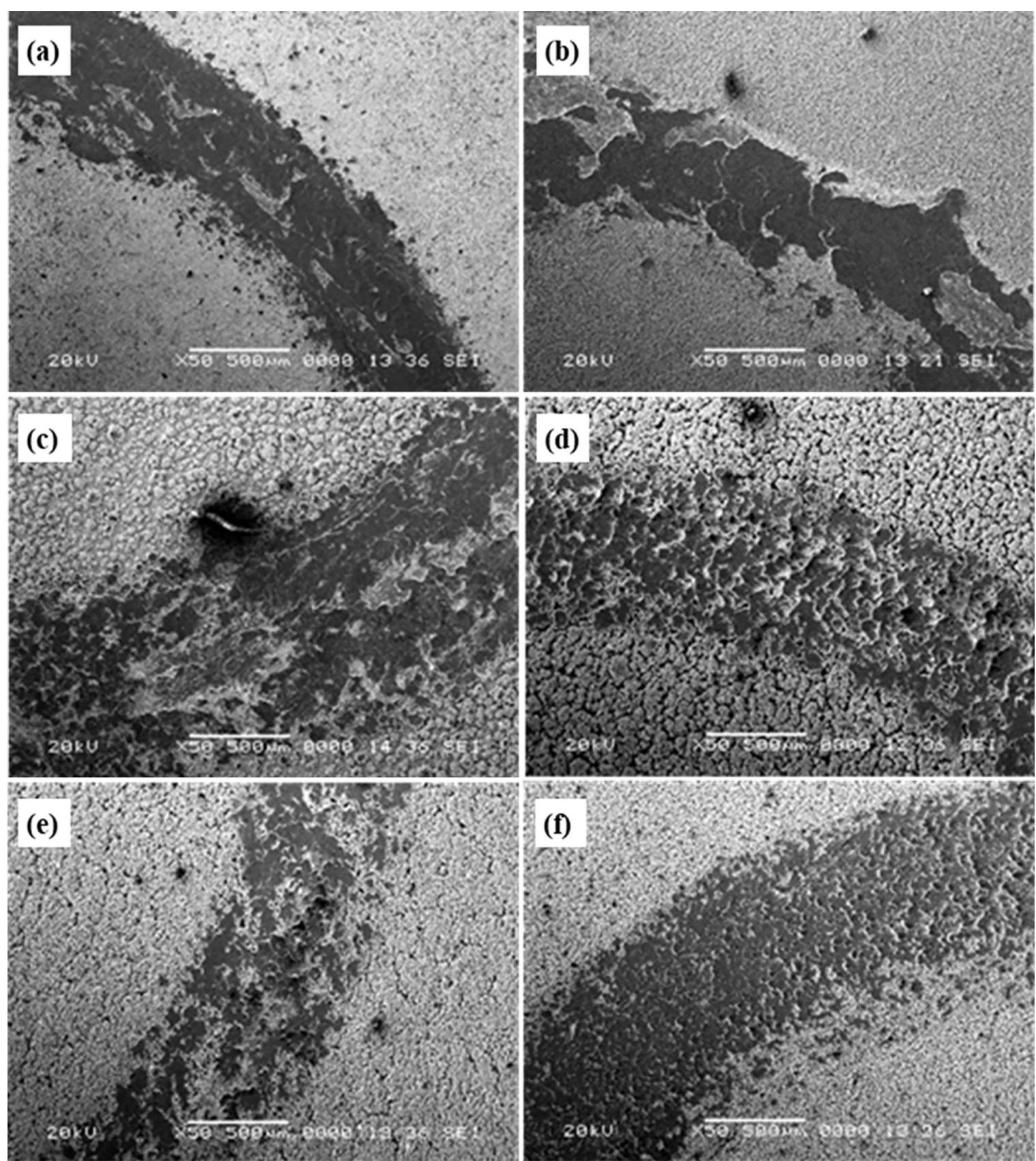

Figure 13. Worn surfaces of Ni-TiC composite coatings with different TiC concentrations in bath: (a) $0 \mathrm{~g} / \mathrm{L}$; (b) $8 \mathrm{~g} / \mathrm{L}$; (c) $16 \mathrm{~g} / \mathrm{L}$; (d) $24 \mathrm{~g} / \mathrm{L}$; (e) $32 \mathrm{~g} / \mathrm{L}$ and (f) $40 \mathrm{~g} / \mathrm{L}$

\section{Conclusions}

Composite coatings consisting of TiC particles embedded uniformly in a nanocrystalline Ni-matrix with minimum grain size of $55.01 \mathrm{~nm}$ were prepared by pulsed electrodeposition. The granular structure evolved to the "cauliflower" structure of the coatings with increasing TiC particles concentration. The optimum value of $\mathrm{TiC}$ particles concentration added in the bath was $32 \mathrm{~g} / \mathrm{L}$. Under this condition, the microindentation hardness of the composite coating and the volume fraction of the $\mathrm{TiC}$ particles in the coating reached the maximum, which were $475 \mathrm{HV}$ and 23.9 vol. \%, respectively.
And the Ni-TiC composite coatings exhibit a considerable enhancement in wear resistance in comparison to pure $\mathrm{Ni}$ coating.

\section{Acknowledgments}

The work was supported by the National Natural Science Foundation of China (50172023) and the Shaanxi Industrial Science and Technology Research (2014K08-09) and the National College Students Innovation Training Program (201910704031). 


\section{References}

1. Song B, Voisey KT, Hussain T. High temperature chlorineinduced corrosion of Ni50Cr coating: HVOLF, HVOGF, cold spray and laser cladding. Surface and Coatings Technology. 2018;337:357-369.

2. Parikh VK, Badgujar AD, Ghetiya ND. Joining of metal matrix composites using friction stir welding: a review. Materials and Manufacturing Processes. 2019;34(2):123-146.

3. Kokabi AH, Allahyari AA. Investigation on the wear properties of $\mathrm{Ti} / \mathrm{TiC} / \mathrm{TiN}$ composite coatings prepared by powder cored wires through TIG method at nitrogen atmosphere on titanium substrate. Materials Research. 2019;22(2):e20180208.

4. Olejnik E, Szymański Ł, Tokarski T, Tumidajewicz M. TiC-based local composite reinforcement obtained in situ in ductile iron based castings with use of rode preform. Materials Letters. 2018;222:192-195.

5. Wang HX, Mao XY. Effect of attapulgite added in plating bath on the properties of $\mathrm{Ni} / \mathrm{TiC}$ nano-composite coatings. Journal Wuhan University of Technology (Materials Science Edition). 2017;32(2):250-255.

6. Saba F, Raygan S. Application of response surface methodology for modelling of TiC coating on AISI D2 steel using a mechanical milling technique. Powder Metallurgy. 2017;60(4):280-292.

7. Gorunov AI. New functional-gradient TiB-TiC-BC-WC coating formed by the method of laser cladding. Metallurgist. 2018;62(7-8):820-830.

8. Liang P, Zhang YX, Shi YH. Research progress of nanostructured nickel-based alloy coatings prepared by pulsed electrodeposition. Corrosion Science and Protention Technology. 2011;23(2):196-200.

9. Li M, Zhang XP, Zhou CL, Tian YQ, Sun QA, Zhang ZF, et al. Research progress of Ni-based nano-composite coatings. Plating and Finishing. 2016;38(11):24-28.

10. Karbasi M, Yazdian N, Vahidian A. Development of electroco-deposited Ni-TiC nano-particle reinforced nanocomposite coatings. Surface and Coatings Technology. 2012;207:587-593.

11. Aruna ST, Muniprakash M, Grips WVK. Effect of titania particles preparation on the properties of $\mathrm{Ni}_{-} \mathrm{TiO}_{2}$ electrodeposited composite coatings. Journal of Applied Electrochemistry. 2013;43(8):805-815.

12. Li YX, Su KQ, Bai PK, Wu LY, Liu B, Su HW, et al. Effect of TiBCN content on microstructure and properties of laser cladding Ti/TiBCN composite coatings. Metals and Materials International. 2019;25(5):1366-1377.

13. Zhang ZH, Wang X, Zhang QQ, Liang Y, Ren L, Li X. Fabrication of Fe-based composite coatings reinforced by TiC particles and its microstructure and wear resistance of $40 \mathrm{Cr}$ gear steel by low energy pulsed laser cladding. Optics and Laser Technology. 2019;119:105622.

14. Berger LM. Application of hardmetals as thermal spray coatings. International Journal of Refractory Metals and Hard Materials. 2015;49(1):350-364.
15. Liu ZD, Tian J, Li B, Zhao LP. Microstructure and mechanical behaviors of in situ $\mathrm{TiC}$ particulates reinforced $\mathrm{Ni}$ matrix composites. Materials Science and Engineering: A 2010;527(1617):3898-3903.

16. Wang GF, Liu ZX, Zhang GP. Effect of milling time on microstructure and mechanical properties of $\mathrm{TiC}-\mathrm{CoCrFeNi}$ composites prepared by hot pressing sintering. Journal of Materials Engineering. 2019;47(6):94-100.

17. Yu PC, Yi DQ, Hu B, Liu HQ. Preparation and microstructure of Ni-coated TiC composite powder by electroless plating. Chinese Journal of Nonferrous Metals. 2013;23(2):439-447.

18. Zhao J, Liu YK, Zhao Q. Optimization of technology of NiTiC composite deposit. Modern Manufacturing Engineering. 2005;(2):129-131.

19. Luo W, Jie XH, Meng YK, Xu J, Tao HL,Wei L. Effect of TiC coating prepared by Iron sputtering with double cathodes on properties of diamond tools. China Surface Engineering. 2012;25(5):26-30.

20. Sun WC, Zhang P, Zhao K, Tian MM, Wang Y. Effect of graphite concentration on the friction and wear of $\mathrm{Ni}-\mathrm{Al}_{2} \mathrm{O}_{3}$ /graphite composite coatings by a combination of electrophoresis and electrodeposition. Wear. 2015;342-343:172-180.

21. Ghazanlou SI, Farhood AHS, Ahmadiyeh S, Ziyaei E, Rasooli A, Hosseinpour S. Characterization of pulse and direct current methods for electrodeposition of Ni-Co composite coatings reinforced with nano and micro $\mathrm{ZnO}$ particles. Metallurgical and Materials Transactions: A. 2019;50(4):1922-1935.

22. Ghazanlou SI, Farhood AHS, Hosouli S, Ahmadiyeh S, Rasooli A. Pulse and direct electrodeposition of Ni-Co/micro and nanosized $\mathrm{SiO}_{2}$ particles. Materials and Manufacturing Processes. 2018;33(10):1067-1079.

23. Qu NS, Chan KC, Zhu D. Pulse co-electrodeposition of nano $\mathrm{Al}_{2} \mathrm{O}_{3}$ whiskers nickel composite coating. Scripta Materialia. 2004;50(8):1131-1134.

24. Feng XJ, Kan HM, Wei XD. Research progress of Ni-based composite coatings prepared by electrodeposition. Surface Technology. 2017;46(5):75-82.

25. Yue WX. Preparation process of Ni-TiN composite coating by ultrasonic assisted pulsed electrodeposition method. Journal of Synthetic Crystals. 2017;46(7):1408-1410.

26. Ataie SA, Zakeri A. Improving tribological properties of (Zn-Ni)/ nano $\mathrm{Al}_{2} \mathrm{O}_{3}$ composite coatings produced by ultrasonic assisted pulse plating. Journal of Alloys and Compounds. 2016;674:315-322.

27. Ghazanlou SI, Shokuhfar A, Navazani S, Yavari R. Influence of pulse electrodeposition parameters on microhardness, grain size and surface morphology of $\mathrm{Ni}-\mathrm{Co} / \mathrm{SiO}_{2}$ nanocomposite coating. Bulletin of Materials Science. 2016;39(5):1185-1195.

28. Guglielmi N. Kinetics of the deposition of inert particles from electrolytic baths. Journal of the Electrochemical Society. 1972;119(8):1009-1012.

29. Hong Q, Yao G, Chen S. Development of iron matrix antifriction composite coatings. Metal Finishing. 1998;96(10):16-19. 